\title{
O PLANO EDUCACIONAL INDIVIDUALIZADO E A ESCOLARIZAÇÃO DOS ALUNOS COM DEFICIÊNCIA INTELECTUAL: POLÍTICAS E PRÁTICAS ${ }^{1}$
}

\author{
EL PLAN EDUCATIVO INDIVIDUALIZADO Y LA ESCOLARIZACIÓN DE LOS \\ ESTUDIANTES CON DISCAPACIDAD INTELECTUAL: POLÍTICAS Y PRÁCTICAS
}

\author{
THE INDIVIDUALIZED EDUCATIONAL PLAN AND THE SCHOOLING OF \\ STUDENTS WITH INTELLECTUAL DISABILITIES: POLICIES AND PRACTICES
}

\author{
Tânia Mara dos Santos BASSI ${ }^{2}$ \\ Vilma Miranda de BRITO ${ }^{3}$ \\ Celi Corrêa NERES ${ }^{4}$
}

\begin{abstract}
RESUMO: Este texto busca apresentar e discutir a execução do Plano Educacional Individualizado (PEI), como instrumento no processo de escolarização de alunos com deficiência, na primeira etapa do Ensino Fundamental. Para tanto, buscou-se, por meio de abordagem qualitativa, realizar um estudo sobre o uso do PEI no processo de inclusão escolar de alunos com deficiência intelectual (DI). Constatou-se que a operacionalização do PEI não ocorre, de maneira direta, para o atendimento de todos os alunos com DI. No entanto, tendo em vista as necessidades educacionais do DI, desenvolvem-se adequações pedagógicas no âmbito da sala de aula comum, principalmente pelo Auxiliar Pedagógico Especializado (APE). Por outro lado, os dados coletados demonstraram que, especificamente, quanto ao professor titular/regente, existe uma fragilidade de conhecimentos sobre a educação especial e suas especificidades, o que interfere diretamente na promoção da escolarização do aluno DI inserido na escola comum.
\end{abstract}

PALAVRAS-CHAVE: Inclusão. Plano educacional individualizado (PEI). Deficiência intelectual. Prática docente.

RESUMEN: Este texto busca presentar y discutir la implementación del Plan Educativo Individualizado (PEI), como instrumento en el proceso de escolarización de los estudiantes con discapacidades, en la primera etapa de la escuela primaria. Con este fin, se buscó, através de un enfoque cualitativo, realizar un estudio sobre el uso de PEI en el proceso de inclusión escolar de los estudiantes con discapacidad intelectual (DI). Se encontró que la puesta en

${ }^{1}$ Este artigo é resultado de uma pesquisa desenvolvida no Programa de Pós-Graduação Stricto Sensu - Mestrado Profissional em Educação/UEMS/MS/Unidade de Campo Grande (2019).

${ }^{2}$ Secretaria de Estado de Educação de Mato Grosso do Sul (SED), Secretaria Municipal de Educação de Campo Grande (SEMED), Campo Grande - MS - Brasil. Professora na Rede Estadual de Ensino de Mato Grosso do Sul e na Rede Municipal de Ensino de Campo Grande. Mestrado em Educação (UEMS). ORCID: https://orcid.org/0000-0002-5904-2198. E-mail: tmbassi66@gmail.com

${ }^{3}$ Universidade Estadual de Mato Grosso do Sul (UEMS), Campo Grande - MS - Brasil. Docente no Programa de Pós-Graduação Mestrado Profissional em Educação. Doutorado em Educação (UFMS). ORCID: http://orcid.org/0000-0002-1573-5339. E-mail: vilmiranda2015@gmail.com

${ }^{4}$ Universidade Estadual de Mato Grosso do Sul (UEMS), Campo Grande - MS - Brasil. Docente no Programa de Pós-Graduação Mestrado Profissional em Educação (UEMS). Pós-Doutorado em Educação (UFMS). ORCID: http://orcid.org/0000-0001-9864-2180.E-mail: celi@uems.br

RPGE- Revista on line de Política e Gestão Educacional, Araraquara, v. 24, n. esp. 2, p. 1015-1034, set. 2020. e-ISSN: 1519-9029 
marcha del PEI no se produce, directamente, para el cuidado de todos los estudiantes con DI. Sin embargo, en vista de las necesidades educativas de la DI, las adaptaciones pedagógicas se desarrollan dentro del aula común, principalmente por el Asistente Pedagógico Especializado (APE). Por otro lado, los datos recogidos mostraron que, especificamente, en lo que respecta al maestro titular/regente, existe una fragilidad de conocimiento sobre la educación especial y sus especificidades, que interfiere directamente en la promoción de la escolarización del estudiante DI insertado en la escuela común.

PALABRAS CLAVE: Inserción. Plan educativo individualizado (PEI). Discapacidad intelectual. Práctica docente.

ABSTRACT: This paper aims to present and discuss the execution of the Individualized Educational Plan (PEI, Portuguese initials), as an instrument in the schooling process of students with disabilities in the first stage of Elementary Education. To do so, we sought, through a qualitative approach, to conduct a study on the use of PEI in the process of school inclusion of students with intellectual disabilities (ID). It was found that the operationalization of the PEI does not occur to all students with ID in a direct way. However, considering the ID students' educational needs, pedagogical adaptations are developed within the scope of the common classroom, mainly by the Specialized Pedagogical Assistant (SPA). On the other hand, the data collected demonstrated that, specifically, regarding the head teacher/regent there is a fragility of knowledge about special education and its specificities, which directly interferes in the promotion of schooling of the ID student inserted in the common school.

KEYWORDS: Inclusion. Individualized educational plan (PEI). Intellectual disability. Teaching practice.

\section{Introdução}

Em 2008, a Política Nacional de Educação Especial na Perspectiva da Educação Inclusiva foi instituída objetivando orientar a inclusão escolar de alunos com deficiência, transtornos globais do desenvolvimento e altas habilidades/superdotação, nos sistemas de ensino, de forma a promover a esses alunos o acesso com participação e aprendizagem no ensino comum. Entretanto, pesquisadores como Neres (2010), Glat e Plestch (2013) têm apontado a dificuldade que a escola apresenta para implementar a educação inclusiva por conta de que, no âmbito escolar, ainda se pratica uma pedagogia homogênea. Lancillotti (2010) também ressalta que o ensino homogêneo ou simultâneo, no qual as peculiaridades dos alunos não são consideradas, não contribui para a inclusão escolar.

Presume-se, então, que a educação na perspectiva inclusiva, ao apregoar $o$ reconhecimento às diferenças, implica em oferecer condições favoráveis ao processo educacional desse alunado, fundamentado em princípios pedagógicos que assegurem o respeito às diferenças. No entanto, “[...] dar igualdade de oportunidades nem sempre significa dispensar 
o mesmo tratamento. A escola deve ter por objetivo oportunizar o mesmo acesso, o que não significa oferecer sempre os mesmos meios" (KASSAR; GOES, 2007, p. 60-61).

Assim, educação inclusiva traz, em seu relevo, a ideia de um projeto de escola pelo qual se torna possível o acesso e a permanência de todos os alunos, onde os mecanismos de seleção e exclusão dão lugar a procedimentos de identificação e remoção de barreiras para a aprendizagem (GLAT, 2013). Nesse caso, requer a formação de professores e equipe gestora, bem como uma revisão das formas de interação vigentes, que respaldam as ações de todos os segmentos da escola. Constitui-se, portanto, num desafio que pressupõe a ressignificação da educação especial para que se possa promover a aprendizagem de todos no ensino comum.

Partindo das reflexões apresentadas nas pesquisas mencionadas, inferimos que alunos com diferentes deficiências têm sido matriculados no ensino comum sem, contudo, o cuidado requerido na adequação de procedimentos pedagógicos, material e outros requisitos básicos na sua escolarização. Apesar das ações disciplinadas nas esferas federal, estadual e municipal, ou seja, da regulamentação legal sobre a inclusão escolar, é inegável que a sua efetivação requer que a escola se ajuste a fim de bem atender a diversidade desse público.

Nessa perspectiva, a Resolução CNE/CEB n. 2/2001, em seu art. 2 ${ }^{\circ}$, institui a obrigatoriedade de matrícula aos sistemas de ensino, definindo que cabe às escolas "[...] organizarem-se para o atendimento aos educandos com necessidades educacionais especiais, assegurando as condições necessárias para uma educação de qualidade para todos". A mesma normativa, em seu art. $8^{\circ}$, orienta que as escolas da rede regular de ensino devem prover, nas classes comuns, flexibilizações e adaptações curriculares, bem como metodologias e recursos didáticos diferenciados e processos de avaliação adequados aos alunos que apresentam necessidades educacionais especiais (BRASIL, 2001). Logo, o Plano Educacional Individualizado (PEI) está aí implícito, pois sua aplicação tem em vista a aprendizagem e o desenvolvimento do aluno com deficiência.

O PEI, enquanto planejamento específico que visa subsidiar a escolarização dos alunos com deficiência, aparece nas entrelinhas dos documentos nacionais e está explícito na Lei n. 4.621/2014 (MATO GROSSO DO SUL, 2014), que instituiu o Plano Estadual de Educação de Mato Grosso do Sul (PEE/MS/2014); na Deliberação n. 1.380/CME/MS/2012 (CAMPO GRANDE, 2012) e na Resolução SEMED/Campo Grande/MS, n. 184/2018 (CAMPO GRANDE, 2018). Nestes documentos o PEI aparece com especificidades, buscando favorecer a perspectiva inclusiva, conforme regulamentada no país.

Em vista disso, e apesar dos avanços dos debates acadêmicos e das produções teóricas, o presente texto intenciona apresentar uma análise da execução do PEI, instrumento utilizado 
no processo de escolarização de alunos com deficiência intelectual (DI), na primeira etapa do Ensino Fundamental, na Rede Municipal de Ensino de Campo Grande, capital do estado de Mato Grosso do Sul (MS).

Tem-se o PEI como uma alternativa que visa oferecer adequadas condições de aprendizado e independência para o aluno com deficiência no âmbito do ensino comum, sem se afastar da dinâmica regular da escola. Segundo Glat e Plestch (2013), o PEI é “[...] uma estratégia para a organização de uma proposta curricular que assiste os alunos com necessidades educacionais [...]" e, também, “[...] é um instrumento de mediação de aprendizagem de alunos com necessidades especiais em situação de inclusão" (GLAT; PLESTCH, 2013, p. 37).

Ressalta-se que o processo de elaboração do PEI é tido como complexo, à medida que presume o envolvimento dos docentes e equipe técnica a fim de planejarem em curto, médio e longo prazos, as práticas pedagógicas para a escolarização do aluno com deficiência. Tal ação necessita de investimento na formação de professores e gestores da educação para que possam sustentar práticas pedagógicas que vislumbrem a inclusão escolar. Ávila (2015) chama a atenção sobre a perda de momentum das ações do PEI, por descontinuidade e carência de políticas públicas específicas que suportem as ações docentes e falta de capacitações e qualificações pontuais sobre o tema.

A iniciativa do município de Campo Grande-MS, ao instituir o PEI, é importante por se tratar de um instrumento que "[...] quebra a barreira do padrão, auxiliando o currículo oficial, especificando e estruturando o tipo de atividade e apontando qual apoio profissional é conveniente [...]" (VALADÃO, MENDES, 2018, p. 6). O entendimento é de que este é um dos caminhos para se avançar na política de escolarização de alunos com deficiência evidenciando a menor arbitrariedade possível e, consequentemente, garantindo uma educação de qualidade para todos.

Portanto, o objetivo principal do deste artigo consiste em traçar um panorama sobre o Plano Educacional Individualizado (PEI), partindo da análise da legislação, passando pela importância do planejamento educacional para o aluno DI e finalizando com a análise da prática do PEI no município de Campo Grande-MS.

\section{Educação especial e Plano Educacional Individualizado (PEI) na educação brasileira: aspectos legais e planejamento}

A educação inclusiva está assentada na defesa de educação para todos. Segundo Pletsch (2014, p. 39), a ideia de educação para todos “[...] ganhou força durante a primeira metade do 
século XX, com a Declaração dos Direitos Humanos, de 1948, na qual se estabeleceu o seguinte princípio: toda a pessoa tem direito à instrução".

Hoje, os direitos sociais, pilares da constituição da cidadania, pressupõem a constituição de novos desafios, novos espaços de ação são estabelecidos por meio das transformações da contemporaneidade e "O direito à educação escolar é um desses espaços que não perderam e nem perderão sua atualidade" (CURY, 2002, p. 246). É, pois, a educação escolar, a base instituidora da cidadania e um direito legal instituído com a Constituição Federal de 1988.

Para Cury (2008, p. 301), “A educação básica, como direito, aprofundou-se no Brasil com a aprovação da Lei n. 11.274/06, pela qual o ensino fundamental obrigatório passou a durar nove anos, iniciando-se aos 6 anos de idade [...]". Nesse sentido, a escolaridade obrigatória surge como resgate de um direito de cidadania. Isso porque,

A declaração e a garantia de um direito tornam-se imprescindíveis no caso de países, como o Brasil, com forte tradição elitista e que tradicionalmente reservam apenas às camadas privilegiadas este bem social. Por isso, declarar e assegurar é mais que uma proclamação solene. Declarar é retirar do esquecimento e proclamar aos que não sabem, ou esqueceram, que eles continuam a ser portadores de um direito importante. Disso resulta a necessária cobrança deste direito quando ele não é respeitado (CURY, 2002, p. 259).

Trata-se de direitos que devem ser prestados sem nenhuma forma de discriminação (BRASIL, 1988). Portanto, ao poder público cabe a obrigação de oferecer os serviços educacionais a todos, conforme os princípios constitucionais, de forma a possibilitar a todos o direito à educação.

No Brasil, a política de educação inclusiva vem sendo construída pelos sistemas de ensino estaduais e municipais, na consolidação de suas bases legais e tem sua gênese no movimento pela universalização da educação básica (PLESTCH, 2014). Com a proposta da educação inclusiva, os alunos com deficiência passaram a ser inseridos nas classes do ensino comum, transformando-se em mais um desafio para o trabalho docente. Isso porque, em consonância com o ensino comum, a política de inclusão, a educação especial deve fazer parte da proposta pedagógica da escola.

A Lei n. 13.146/2015, denominada lei Brasileira de Inclusão (LBI), também conhecida como Estatuto da Pessoa com Deficiência, ratifica que a educação constitui direito da pessoa com deficiência, sinalizando para o aprimoramento dos sistemas de ensino, a fim de que haja a inclusão plena. A referida lei orienta para a adoção de medidas individualizadas e coletivas em ambientes que maximizem o desenvolvimento acadêmico e social dos estudantes com 
deficiência, favorecendo o acesso, a permanência, a participação e a aprendizagem em instituições de ensino (BRASIL, 2015). Esses pressupostos da LBI aproximam a ideia do desenvolvimento do PEI, tendo em vista uma prática educacional na perspectiva da educação inclusiva.

A LBI, de modo amplo, trata do acesso às garantias e direitos para as pessoas com deficiência, nas diversas áreas. Na Educação, elucida a inibição da recusa de matrícula de aluno com deficiência no ensino regular, inclusive na educação privada, ratificando o que apregoa a Constituição Federal (BRASIL, 1988) e o Plano Nacional de Educação PNE/2014 (BRASIL, 2014), ou seja, o reconhecimento do respeito à valorização da diversidade e os princípios de equidade, chamando para o poder público a responsabilidade de garantir o acesso à educação.

O PNE estabelece diretrizes para as políticas públicas, bem como metas para serem alcançadas e as estratégias para a implementação e concretização da legislação educacional brasileira para o decênio 2014-2024, priorizando a universalização do acesso à educação (BRASIL, 2014). Consonante com essa política pública mais abrangente, os planos de educação estaduais e municipais foram elaborados alinhados ao PNE.

Especificamente quanto à educação especial, O PEE/2014 apresenta estratégias e direcionamentos para garantir e assegurar o objetivo de

Universalizar o acesso à educação básica para a população de 4 a 17 anos com deficiência, transtornos globais do desenvolvimento e altas habilidades ou superdotação, de preferência na rede regular de ensino, com a garantia de sistema educacional inclusivo, de salas de recursos multifuncionais, classes, escolas ou serviços especializados, sejam esses públicos ou conveniados (MATO GROSSO DO SUL, 2014, p. 17).

Na Estratégia 4.26, o PEE/2014, ao se referir a uma proposta pedagógica acessível, faz referência ao PEI como instrumento para essa possibilidade, quando refere: “[...] propiciar aos estudantes com deficiência, transtornos globais do desenvolvimento e altas habilidades uma proposta pedagógica acessível, nas escolas comuns, com a utilização do Plano Educacional Individualizado (PEI)" (MATO GROSSO DO SUL, 2014, p. 17).

O Plano Municipal de Educação do município de Campo Grande/MS (PME 20152025), instituído pela Lei n. 5.565/2015 (CAMPO GRANDE, 2015), faz menção genérica sobre o PEI e sua regulamentação ficou a cargo da Resolução SEMED n. 184/2018 (CAMPO GRANDE, 2018). No entanto, constata-se que, ao fazer as considerações sobre as condições específicas dos alunos, assegura: 
[...] o acesso à educação básica e ao atendimento educacional especializado, preferencialmente na rede regular de ensino, com a garantia de sistema educacional inclusivo, de salas de recursos multifuncionais, classes, escolas ou serviços especializados, públicos ou conveniados.

4.8 garantir a oferta de educação inclusiva, vedada a exclusão do ensino regular sob alegação de deficiência; 4.8.1 promover a articulação pedagógica entre o ensino regular e o atendimento educacional especializado, favorecendo o desenvolvimento e a aprendizagem, por meio dos recursos e apoios especializados. 4.20 estabelecer mecanismos alternativos de avaliação, considerando as especificidades do alunado e os recursos disponíveis (CAMPO GRANDE, 2015).

Nesse sentido, entende-se que a perspectiva da educação e, impelida pela Convenção sobre os Direitos das Pessoas com Deficiência (CDPD), aprovada pela Organização das Nações Unidas (ONU, 2006) e, no Brasil, pela Constituição Federal (1988), por decretos e Planos de Educação, vem garantindo aos alunos com deficiência o acesso ao ensino comum tendo, por meio do PEI, a possibilidade do atendimento às suas necessidades educativas especiais.

É importante destacar que o PEI, no Brasil, vem se configurando com iniciativas isoladas, como uma estratégia norteadora das ações pedagógicas, com a finalidade de contribuir para a inclusão de alunos com necessidades educacionais especiais no ensino comum.

No planejamento do PEI, materializado num formulário, registram-se as necessidades educacionais especiais do aluno, de acordo com a observação e avaliação escolar prévia, bem como com as demais informações disponíveis pelos partícipes no processo, e compõe o processo educacional individual do aluno. Contudo, reiterando a ideia de que pode ser uma estratégia eficaz ao facilitar e orientar a organização curricular, a fim de auxiliar no processo de ensino e aprendizagem do aluno com deficiência, requer ampliar estudos nesse campo para validá-lo, já que é “[...] uma prática pouco aplicada” (GLAT, VIANNA E REDIG, 2012, p. 97).

Nesse sentido, em âmbito nacional, “[...] não há propostas na legislação, de procedimentos ou normas oficiais que sejam claras e assegurem ao aluno com deficiência uma avaliação adequada e um planejamento educacional individualizado" (VALADÃO, 2010, p. 95). Mas é importante ressaltar que existem documentos nacionais que apontam para a necessidade de individualização do ensino de maneira a favorecer os processos de inclusão. Um exemplo é o documento do MEC intitulado "Adaptações Curriculares de Grande Porte 5". O referido documento informa que:

[...] alunos com necessidades educacionais especiais devem ter um Plano Individualizado de Ensino, quando se fizer necessário, podendo ser elaborado com apoio do ensino especial no início de sua vida escolar, e por ela, atualizado continuamente, em função de seu desenvolvimento e aprendizagem. Esse Plano é o ponto fundamental de sua vida escolar, 
norteador das ações de ensino do professor e das atividades escolares do aluno (BRASIL, 2000, p. 24, grifo nosso).

Outro documento que dispõe sobre a Educação Especial, que traz em suas diretrizes a ideia de diferenciação e individualização, é o Decreto n. 7.611/2011, que estabelece, no artigo $1^{\circ}$, a obrigatoriedade de assegurar que haja:

[...] garantia de ensino fundamental gratuito e compulsório, com base na igualdade de oportunidades, asseguradas adaptações razoáveis de acordo com as necessidades individuais; adoção de medidas de apoio individualizadas e efetivas, em ambientes que maximizem o desenvolvimento acadêmico e social, de acordo com a meta de inclusão plena (BRASIL, 2011, grifo nosso).

Logo, observa-se que o PEI aparece de forma implícita no aparato legal brasileiro, uma vez que trata, apenas, da individualização do ensino e é percebido como alternativa metodológica facilitadora no processo inclusivo, indicando que sua aplicação pode colaborar para a qualidade da aprendizagem e do desenvolvimento do aluno com deficiência.

A ação pedagógica na escolarização de alunos com deficiência, considerando suas necessidades educacionais, impõe a busca de alternativas pedagógicas que favoreçam sua participação escolar. Isso se torna mais evidente ao se tratar do aluno com deficiência intelectual, tida como complexa quando comparada às demais deficiências. Corroborando com esta afirmação, Rodrigues (2009) assegura que:

De todas as experiências que surgem no caminho de quem trabalha com a inclusão, receber um aluno com Deficiência Intelectual parece a mais complexa. Para o surdo, os primeiros passos são dados com a Língua Brasileira de Sinais (Libras). Os cegos têm o braile como ferramenta básica e, para os estudantes com limitações físicas, adaptações no ambiente e nos materiais costumam resolver os entraves do dia-a-dia (RODRIGUES, 2009, p. 23).

Evidencia-se, portanto, a complexidade da deficiência intelectual. Nesse sentido, o PEI como estratégia de organização curricular tende a contribuir no processo de ensinoaprendizagem desses alunos. Isso porque o PEI é compreendido como um recurso para instrumentalizar, de forma mais efetiva, propostas pedagógicas que contemplem as demandas de cada aluno, a partir de objetivos gerais elaborados para a turma (GLAT; PLESTCH, 2009; 2012; 2013; POKER, 2013). É concebido como um esboço da situação do aluno, de suas necessidades e de como estas deveriam ser atendidas. Ele está sujeito a semelhantes princípios que os demais planos efetivos de educação e ensino, e cuja diferença está no layout. $\mathrm{Na}$ percepção de Pacheco (2007, p. 100), “[...] a natureza prática do PEI depende de quão bem o ajuste educacional é atingido e quão bem o plano é conectado ao trabalho geral da turma". 
Deduz-se, então, que o cerne da estrutura do PEI está na conexão com o currículo geral da turma e, ao mesmo tempo, no detalhamento e ajuste ao aluno.

Dessa maneira, o PEI tem como premissa redimensionar as práticas pedagógicas nas ações desenvolvidas por professores da classe comum e do professor do Atendimento Educacional Especializado (AEE) que, por meio do trabalho colaborativo, possibilitam a participação e o desenvolvimento do aluno com deficiência junto aos seus pares.

Pode-se dizer que a elaboração do PEI propicia práticas de ensino customizadas, personalizadas a partir de peculiaridades do aluno. Nesse sentido, Glat e Plestch (2013) mencionam que a elaboração do PEI envolve diferentes etapas: identificação, avaliação e intervenção. Assim, com o propósito de conhecer o nível de desenvolvimento escolar do aluno com deficiência, constitui-se o inventário de habilidades escolares, o qual requer ser elaborado, aplicado e avaliado por conter pistas sobre as habilidades existentes e as em processo, elucidando elementos relevantes na constituição do PEI.

Assim, a elaboração do PEI deve contar com todos os membros da comunidade escolar que atuam junto ao aluno, além da família. Emerge de um apanhado das características gerais apresentadas pelo aluno, bem como de suas necessidades, constituindo-se de um registro escrito avaliativo, formulado em equipe, em que se procura propor respostas educativas adequadas às necessidades educacionais que se apresentam no processo de escolarização do aluno com deficiência que necessite de meios alternativos para o alcance de sua aprendizagem. Para tanto, tem-se como procedimentos importantes: a observação, a avaliação pedagógica compreensiva sobre o aluno e as informações complementares dispostas pelos constituintes envolvidos no processo. Dessa forma, considera-se o educando em seu estágio atual de habilidades, conhecimento, desenvolvimento, idade cronológica, nível de escolarização em que se encontra e, a partir desses, os objetivos educacionais almejados a curto, médio e longo prazos (GLAT; PLESTCH, 2013).

Ressalta-se que não se trata de beneficiar um aluno com deficiência em detrimento dos demais, mas, sim, de propor estratégias diferenciadas, individualizadas de ensino, bem como utilizar recursos e linguagens diversificados, adequando tempo e espaço escolar, reconsiderando, inclusive, os procedimentos e critérios avaliativos, tendo em vista as necessidades que se apresentam (ANDRÉ, 1999). Nessa premissa, o PEI constitui-se em uma estratégia didática norteadora, que se traduz em respostas educativas às necessidades específicas com vistas a beneficiar o processo de escolarização de alunos que apresentam deficiência intelectual, matriculados em ensino comum. Pode-se dizer que o PEI se materializa 
no formulário como instrumento didático, mas que acaba se tornando uma estratégia pedagógica pela amplitude de ações inseridas e previstas.

Assim, a próxima seção tem o intuito de refletir sobre a organização, o planejamento e a implementação do trabalho pedagógico desenvolvido no atendimento dos alunos com deficiência na escola comum, de maneira a investigar a garantia efetiva do direito ao acesso, à permanência e ao conhecimento escolar.

\section{$O$ atendimento a alunos com deficiência em Campo Grande/MS}

No município de Campo Grande-MS, o ordenamento legal para o atendimento aos alunos com deficiência, no ensino comum, tem regulamentado ações e medidas individualizadas e coletivas na execução dos planos relacionados ao Atendimento Educacional Especializado. Assim, apesar de não apontar diretamente o PEI, os documentos legais o incluem.

No entanto, no estado de Mato Grosso do Sul, o PEI está previsto no aparato legal sobre a educação especial. Ressalta-se, aqui, que a Deliberação CME/MS n. 1.380/2012, ao dispor sobre a Educação de alunos com deficiência, Transtornos Globais de Desenvolvimento, Altas Habilidades/Superdotação, abrangendo todas as etapas e modalidades da Educação Básica, ampliou o raio de ação do PEI para todo o Ensino Fundamental no estado de Mato Grosso do Sul, o que passou a exigir maior compromisso do poder público em atender essa demanda de alunos e, particularmente, alunos com deficiência intelectual.

Já no município de Campo Grande, a Resolução SEMED n. 154/2014 (CAMPO GRANDE, 2014) dispõe sobre a Educação Especial em todas as etapas e modalidades da educação básica da Rede Municipal de Ensino, elencando como apoio pedagógico especializado os seguintes recursos: Tradutor Intérprete de Libras - Língua Portuguesa; Auxiliar Pedagógico Especializado; Atendimento Educacional Especializado oferecido em Sala de Recursos Multifuncionais; Assistente de Inclusão Escolar e Tutor estagiário de Pedagogia. Além desses recursos, definiu-se uma equipe técnica responsável na SEMED para o acompanhamento dos trabalhos nas escolas que atendem o ensino fundamental e nas escolas de educação infantil.

Com a finalidade de subsidiar o processo de aprendizagem de alunos com deficiência, a equipe técnica denominada Departamento de Educação Especial (DEE/SEMED) implantou, em 2007, seis Núcleos de Acompanhamento Psicopedagógico denominados NUMAPS. Esses núcleos foram organizados por polos e têm como incumbência o acompanhamento sistemático 
às escolas da REME, a fim de viabilizarem a inclusão escolar de alunos com deficiência, possibilitando a estes o processo de construção do conhecimento. Esses Núcleos “[...] foram implantados como estratégia de suporte a partir do acompanhamento especializado a alunos e professores" (NERES; CORREAA, 2009, p. 13).

Cabe ressaltar que a SEMED, ao primar pela educação inclusiva para contribuir com o desenvolvimento do potencial de todos os alunos, independentemente das limitações apresentadas, valeu-se de recursos que, de fato, pudessem contribuir para o alcance de tais objetivos.

É fato que há desafios de várias ordens nos pressupostos da inclusão escolar, inclusive nas interfaces entre os setores de Saúde e Educação e no provimento de encaminhamentos nesse sentido. A inclusão, como se vê, não se restringe a, meramente, um encaminhamento escolar, e, diga-se de passagem, mesmo o diagnóstico feito por um especialista da área da saúde não a garante, posto que não se resume a mera presença desse alunado na escola.

De acordo com o levantamento realizado no processo de coleta de dados para a pesquisa, a REME de Campo Grande-MS mantinha 108 escolas que atendiam o ensino fundamental, no ano de 2018, mas mantinha, apenas, 65 salas de recursos. Conforme dados da DEE/SEMED/2018, dentre o quantitativo geral de salas de recursos, apenas três realizavam atendimentos específicos a alunos com surdez; duas mantinham atendimentos voltados para alunos com baixa visão e cegueira e uma desenvolvia atendimentos a alunos com altas habilidades. O restante das salas de recursos (59) eram salas multifuncionais, que atendiam todas as especificidades, dentre as quais os alunos com DI (CAMPO GRANDE, 2018).

Portanto, o levantamento evidenciou a existência de atendimento às diferentes deficiências, em toda a rede municipal de ensino. Mas um fato que chamou a atenção, o quantitativo de alunos com DI, uma vez que o mesmo excede as demais deficiências, como se pode observar na tabela 1 .

Tabela 1 - Dados de atendimento a alunos com deficiências - Rede Municipal de Ensino de Campo Grande-MS - 2018

\begin{tabular}{l|c}
\multicolumn{1}{c|}{ Especificação } & Quantidade \\
\hline Deficiência Física & 100 \\
\hline Paralisia Cerebral & 368 \\
\hline Cegueira & 21 \\
\hline Baixa Visão & 51 \\
\hline Deficiência Auditiva & 45 \\
\hline Surdez & 100 \\
\hline Altas Habilidades & 27 \\
\hline
\end{tabular}




\begin{tabular}{l|c}
\hline Deficiência Intelectual & 774 \\
\hline Síndrome de Down & 84 \\
\hline Transtorno do Espectro Autista & 385 \\
\hline Transtornos Globais do Desenvolvimento & 31 \\
\hline Deficiências Múltiplas & 174 \\
\hline Total & $\mathbf{2 . 1 3 3}$ \\
\hline
\end{tabular}

Fonte: Campo Grande/SEMED/DEE/ (2018)

Esses dados evidenciam significativo número de alunos com deficiência matriculados na REME. No cômputo geral são 2.133 alunos e, dentre eles, destaca-se o alto quantitativo de diagnóstico de deficiência intelectual (36\%), seguidos de alunos TEA, 18,04\%, e os que apresentam Paralisia Cerebral (cujo distúrbio motor advém de lesão cerebral), com 17,25\%. É importante informar que o grupo definido como deficiências múltiplas abrange alunos que apresentam duas ou mais deficiências primárias (intelectual, visual, física) e representa 8,15\% do total de atendimentos. Esclarece-se, também, que no grupo deficiência física $(4,68 \%)$ estão aqueles com limitações na mobilidade e locomoção, afetados por amputação, malformação e patologias degenerativas.

Os dados empíricos da pesquisa foram coletados, inicialmente, por meio de informações oficiais junto a DEE/SEMED acerca do quantitativo de alunos da Educação Especial, por escola, no âmbito da REME. A partir daí, definiu-se a seleção das escolas e optou-se por investigar os alunos com DI, em virtude do alto quantitativo de alunos atendidos com essa deficiência. Posteriormente, realizou-se entrevista semiestruturada com os seguintes sujeitos: professor regente, APE, estagiário e Técnico do NUMAPS/DEE. O intuito das entrevistas foi de levantar questões sobre a formação profissional e a prática pedagógica no tocante ao Plano Educacional Individualizado e a escolarização de alunos com deficiência intelectual.

Duas escolas municipais foram selecionadas para a pesquisa, sendo uma localizada na região central e outra na periferia do município. A escola A localiza-se no bairro Monte Líbano, caracterizado por alto adensamento urbano, sendo atendido com toda a infraestrutura e serviços públicos disponíveis. A escola B é localizada no bairro Portal Caiobá, caracterizado como área de adensamento futuro por não estar, totalmente, habitado (CAMPO GRANDE, 2017).

As escolas A e B dispõem de uma boa equipe de especialistas, quais sejam: diretor, supervisor, coordenador. Em ambas, se observou que há alunos incluídos em classes comuns, nos diferentes turnos de funcionamento. A distribuição, isto é, a formação das turmas ocorre de modo que haja, no máximo, três alunos com deficiência por sala, otimizando o trabalho do APE, quando necessário. A título de esclarecimento, a Resolução SEMED n. 184/ 2018 permite até, no máximo, seis alunos com deficiência por turma (CAMPO GRANDE, 2018). 
Por razões éticas, a identificação das escolas e dos profissionais entrevistados foi omitida. As escolas foram identificadas, apenas, como escola A (situada na região Central) e escola B (situada na região da Lagoa). Os entrevistados, por sua vez, foram identificados por numeração. Assim, temos: professor 1, 2 e 3, APE 1 e 2, Estagiário 1 e técnicos 1 e 2.

Considerando que o PEI foi regulamentado na REME muito recentemente, buscou-se saber dos entrevistados como tem sido oferecido o suporte especializado e quais os atores indispensáveis para que o mesmo possa ser efetivado no atendimento ao aluno na rede municipal de ensino.

Dessa forma, uma questão sensível no desenvolvimento da pesquisa foi a de conhecer como o PEI era desenvolvido na sala de aula. De acordo com a orientação pedagógica e com a normatização da SEMED, por meio da Resolução n. 184/2018 (CAMPO GRANDE, 2018), esse processo deve ser feito a várias mãos, ou seja, deve envolver o professor regente, o APE, o professor do AEE - que dá suporte - e o estagiário na escola que comporta esse recurso humano.

A técnica 1 deu informações sobre como o planejamento do PEI vem sendo encaminhado nas escolas municipais:

Então, com Deficiência Intelectual se tem um profissional na sala que atende outra deficiência, por exemplo, um autista. E aí o aluno com Deficiência Intelectual entra como carona, que a gente fala, ai esse profissional desenvolve.... Mas se não tem [autista], é o professor da sala de recursos que faz junto com o professor Regente. Ainda se está operacionalizando isso, não são todas as escolas que têm essa disponibilidade do professor regente que não tem ninguém na sala, mas se tem um estagiário, a gente já está pedindo para o estagiário fazer. [...] a gente dá as orientações para conduzir esse PEI (TÉCNICA 1).

Essa visão nos leva à constatação de que o PEI não tem sido uma prática constante em sala de aula com alunos DI, mas que é executado quando existem alunos com outras deficiências o que, necessariamente, pressupõe que haja um profissional especializado na sala de aula ou mesmo um estagiário.

É importante ressaltar que, com relação ao aluno DI, não fícou claro se esse procedimento é realmente realizado. No caso das outras deficiências, as entrevistas encaminharam-se para a constatação de que o PEI é operacionalizado.

Cabe lembrar que a LDB n. 9394/96, em capítulo próprio sobre a Educação Especial, assegura a esse público-alvo, professores com especialização para o atendimento especializado, bem como professores do ensino regular, capacitados para inclusão desses alunos em classes comuns. Logo, a fala da técnica 1 evidencia um duplo entrave na prática pedagógica: por um 
lado o professor titular enfrenta barreiras relacionadas às lacunas existentes na formação em serviço ou continuada sobre o PEI; por outro lado, o estagiário está em processo de formação acadêmica e, portanto, pode ainda não contar com pleno domínio técnico para exercer tal atividade.

A entrevistada evidenciou, na sua fala, a existência de uma atitude que está na contramão do que se requer para a educação especial na perspectiva inclusiva, que é o fato de o atendimento ao DI ser realizado como "carona". Entende-se que essa atitude negligencia o direito à igualdade de oportunidades de acesso ao currículo escolar, que deveria ocorrer para todos os alunos.

Cabe destacar que o PEI contribui na definição de apoio e/ou suporte necessário, por meio do levantamento de informações relevantes sobre o aluno e que são obtidas segundo um roteiro denominado inventário/sondagem. Sobre a importância dessa questão de avaliação pedagógica inicial, de sondagem ou inventário, Ávila (2015, p. 90) corrobora afirmando que “[...] serve de material para melhor observação do seu aluno no sentido de auxiliar no planejamento das atividades pedagógicas, bem como a reavaliação das mesmas. Também na proposição de acessibilidade ao currículo, [...] e garantia de sistemas de suporte e apoios".

Sobre a questão do planejamento, a P2 informou que faz, apenas, um para a sala toda e que o PEI é realizado pela APE. A APE2 informou que, de fato, realiza o planejamento para cada um dos alunos que acompanha. Mas, curiosamente, quando foi solicitado que ela disponibilizasse os referidos PEIs, ela apresentou, somente, do aluno que apresentava diagnóstico PC/DI, sem dar informações sobre o atendimento aos demais alunos, ou seja, o DI e o Down que acompanhava.

$\mathrm{Na}$ entrevista com o APE 1, ele informou que:

Com o aluno TEA, eu faço o PEI dele e procuro seguir o que eu coloquei no PEI para a gente trabalhar no bimestre. [...] O outro aluno DI não tem. No direcionamento dessas questões os dois alunos, o TEA e o DI, que eu acompanho, eles não seguem a turma, eles não são alfabetizados ainda (APE1).

O APE1 deixou claro que realizava o PEI somente para o aluno com Transtorno do Espectro Autista (TEA). Nesse caso, subtende-se que a deficiência intelectual é vista como secundarizada.

Na organização do trabalho didático, no que se refere ao planejamento pedagógico do professor titular de sala, constatou-se princípios de homogeneização em detrimento da heterogeneidade. Na fala dos entrevistados, ficou caracterizada a necessidade de se estabelecer 
efetiva articulação e orientação ao professor titular, por parte do professor do AEE e do setor responsável pela educação especial no município.

Sobre os dados levantados pode-se dizer que a pesquisa sinalizou uma aparente incoerência entre o aspecto legal e a prática realizada na escola, uma vez que se constatou que não há clareza sobre o desenvolvimento do PEI ao DI. Há indícios de que o atendimento ocorra de modo isolado e incipiente.

Nota-se que tem sido realizadas adequações, no entanto essa prática está voltada ao trabalho do APE. Mesmo assim, depreende-se das entrevistas, o pouco envolvimento desse profissional e o professor titular/regente da turma. Observa-se situações em que o professor busca promover as adequações a seu modo, como P3, da Escola B. Outros, como a regente P2Escola B, que demonstram insegurança na promoção de adequação. Ademais, há pouca interação da equipe técnica da educação especial com o professor titular, ocorrendo mais notadamente entre especialistas.

Como justificativa para as dificuldades enfrentadas no planejamento e implementação do PEI, a Técnica 2 ressaltou que "[...] ele ainda é muito novo, nem todos os professores, principalmente os professores regentes têm assim o conhecimento exato". Já o P1 - Escola A, informou que o PEI é feito totalmente pelo professor APE. Ressaltou: “[...] Ele faz para os alunos [...] A partir do que eu faço de planejamento, ele faz o PEI a partir do que eu faço".

Logo, infere-se que, de fato, o PEI ainda é uma estratégia a se construir na rede municipal de ensino de Campo Grande, sendo que o primeiro caminho a ser tomado é o de investimento na formação continuada com todos os envolvidos no trabalho, principalmente o professor regente.

Os dados coletados demonstraram que a efetivação da inclusão do aluno com deficiência segue comprometida em virtude das lacunas existentes na organização do apoio especializado, da carência de formação continuada/em serviço, principalmente direcionadas aos professores das escolas comuns, os quais, em última instância, tem maior necessidade de conhecimento que os ajudem no exercício de práticas pedagógicas que possam atender às necessidades educacionais dos alunos.

\section{Considerações Finais}

O estudo possibilitou conhecer e analisar o processo de operacionalização do PEI para o aluno DI inserido no ensino comum, na Rede Municipal de Ensino (REME) de Campo Grande-MS e identificar quais os serviços de apoio oferecidos. 
Observou-se que a política de inclusão vem repercutindo positivamente, no sentido de, a cada ano, ter aumentado o atendimento dos alunos com deficiência, em salas de aula comuns nas escolas da REME de Campo Grande-MS. Não obstante, diante da demanda ampliada, houve a expansão dos serviços de apoio, bem como do quantitativo de salas de recursos.

Logo, infere-se a observância à Constituição Federal (BRASIL,1988), às diretrizes da Política Nacional de Educação Especial (BRASIL, 2008), à LDBN n. 9394/96 (BRASIL, 1996), ao Plano Nacional de Educação (BRASIL, 2014) e ao Plano Municipal de Educação (CAMPO GRANDE, 2015), no que tange à escolarização de alunos com deficiência, pois se constatou o esforço, por parte da REME, em implementar ações para se efetivar a educação inclusiva.

Na prática escolar, os dados apontam a elaboração do PEI junto a alunos com outras especificidades, como TEA e PC, que têm o apoio escolar do APE. Ao aluno DI, a operacionalização desse plano individualizado se constitui de forma incipiente. Na Escola A, a operacionalização do PEI, pelo APE, ocorre apenas para os alunos com diagnóstico de TEA. Praticamente o mesmo se aplica à Escola $\mathrm{B}$, em que se evidenciou a operacionalização do PEI, pelo APE, ao aluno PC/DI. Depreende-se que a deficiência intelectual é secundarizada, pois na fala dos entrevistados esse aluno é tido como "carona".

Teoricamente, o PEI se caracteriza pela forma colaborativa que pressupõe sua elaboração (GLAT; PLESTCH, 2013). Entretanto, os dados empíricos evidenciaram que a prática do PEI se volta para ação do APE, quando existe, demonstrando que ainda há pouco envolvimento do professor titular de sala. O planejamento conjunto de fato não ocorre, apenas o apoio em sala de aula. Ainda, conforme se constatou nas entrevistas realizadas, o planejamento do regente de sala (comum) expressa uma concepção homogênea, com um planejamento único.

Concluímos que promover uma organização pedagógica para o aluno DI vai além da tentativa e improvisação, remete à necessidade de formação continuada que possibilite uma perspectiva reflexiva crítica sobre sua aprendizagem, bem como sobre a ação pedagógica que se desenvolve, superando as dificuldades, a fim de intervir, pedagogicamente, com mais propriedade sobre o processo de aprendizagem do aluno DI. A elaboração do PEI é entendida como alternativa que possibilita ao alunado com deficiência uma melhor condição de acesso ao currículo, no âmbito do ensino comum.

Os dados apresentados também evidenciaram a necessidade de desmistificar que o aluno com deficiência é atribuição exclusiva da educação especial, como apêndice do ensino comum, sendo possível inferir a necessidade do provimento de formações continuadas aos professores. 
De acordo com pressupostos da inclusão, há necessidade de atender as peculiaridades que emergem no contexto escolar. Caso contrário, como advertem Góes e Laplane (2013), há o risco de se implementar a inclusão por meio, unicamente, da matrícula no ensino comum, ignorando necessidades específicas. Portanto, torna-se mister, o investimento do poder público municipal em formação continuada, organizada de modo que os conhecimentos específicos não se fechem no nicho próprio dos profissionais da área, mas que abranjam, principalmente, o professor titular, considerando, na abordagem, a prática pedagógica na perspectiva da educação inclusiva e a operacionalização do PEI.

\section{REFERÊNCIAS}

ANDRÉ, M. (org.). Pedagogia das diferenças na sala de aula. Campinas: Papirus, 1999.

BRASIL. Constituição da República Federativa do Brasil. Brasília: Senado Federal, 1988.

BRASIL. Lei n. 9.394, de 20 de dezembro de 1996. Lei de Diretrizes e Bases da Educação Nacional. Brasília, 23 dez. 1996. Disponível em:

http://www.planalto.gov.br/ccivil_03/leis/19394.htm. Acesso em: 18 fev. 2019.

BRASIL. Projeto Escola Viva: Garantindo o acesso e permanência de todos os alunos na escola - Alunos com necessidades educacionais especiais, Adaptações curriculares de grande porte. Brasília: Ministério da Educação, Secretaria de Educação Especial, 2000.

BRASIL. Resolução CNE/CEB n. 02, de 11 de setembro de 2001. Institui as Diretrizes Nacionais para a Educação Especial na Educação Básica. Brasília, 14 set. 2001. Disponível em: http://portal.mec.gov.br/cne/arquivos/pdf/CEB0201.pdf. Acesso em: 18 fev. 2019.

BRASIL. Secretaria de Educação Especial. Política Nacional de Educação Especial na Perspectiva da Educação Inclusiva. Brasília, DF, jan. 2008. Disponível em: http://portal.mec.gov.br/arquivos/pdf/politicaeducespecial.pd. Acesso em: 18 fev. 2019.

BRASIL. Decreto n. 7.611, de 17 de novembro de 2011. Dispõe sobre a Educação Especial, o atendimento educacional especializado e dá outras providências. Brasília, 18 nov. 2011. Disponível em: http://www.planalto.gov.br/ccivil_03/_ato20112014/2011/decreto/d7611.htm. Acesso em: 18 fev. 2019.

BRASIL. Lei n. 13.005 de 25 de junho de 2014. Plano Nacional de Educação - PNE. Brasília, 26 jun. 2014. Disponível em: http://www.planalto.gov.br/ccivil_03/_ato20112014/2014/lei/113005.htm. Acesso em: 15 jun. 2017.

BRASIL. Lei n. 13.146, de 6 de julho de 2015. Lei Brasileira de Inclusão (Estatuto da Pessoa com Deficiência). Disponível em: http://www.planalto.gov.br/ccivil_03/_ato20152018/2015/lei/113146.htm. Acesso em: 15 jun. 2017. 
CAMPO GRANDE. Deliberação CME/MS n. 1.380, de 3 de agosto de 2012. Campo Grande, 2012. Disponível em: https://www.campogrande.ms.gov.br/cme/downloads/del-n13802012-alunos-com-deficiencias-transtornos-globais-altas-habilidadessuperdotacao. Acesso em: 11 nov. 2017.

CAMPO GRANDE. Resolução SEMED n. 154, de 21 de fevereiro de 2014. Dispõe sobre a educação dos alunos com deficiência em todas as etapas e modalidades da educação básica da Rede Municipal de Ensino de Campo Grande - MS. Campo Grande, 2014.

CAMPO GRANDE. Lei n. 5.565, de 23 de junho de 2015. Aprova o Plano Municipal de Educação do Município de Campo Grande - MS e dá outras providências. Diogrande de 24 jun. 2015. Campo Grande, 2015. Disponível em: http://www. campogrande.ms.gov.br/cme/downloads/plano-municipal-de-educacao-campograndems pme-2015-2025. Acesso em: 10 abr. 2018.

\section{CAMPO GRANDE. O Plano Diretor de Desenvolvimento Urbano Ambiental (PDDUA)} do Município de Campo Grande. Campo Grande, 2017. Disponível em:

http://planodiretorcampogrande.com.br/ page7/page7.html. Acesso em: 31 maio 2018.

CAMPO GRANDE. Resolução SEMED n. 184, de 31 de janeiro de 2018. Dispõe sobre a inclusão do aluno público alvo da Educação Especial na Rede Municipal de Ensino de Campo Grande-MS. Campo Grande, 2018.

CURY, C. R. J. A educação básica no Brasil. Educação \& Sociedade, Campinas, v. 23, n. 80, p. 168-200, set. 2002.

CURY, C. R. J. A educação básica como direito. Cadernos de Pesquisa, São Paulo, v. 38, n. 134, p. 293-303, maio/ago. 2008.

GLAT, R. A educação inclusiva: cultura e cotidiano escolar. Rio de janeiro: 7 Letras, 2013.

GLAT, R.; PLETSCH, M. D. A escolarização de alunos com deficiência intelectual: uma análise de aplicação do plano de desenvolvimento educacional individualizado. Linhas Críticas, Brasília, DF, v. 18, n. 35, p. 193-208, jan./abr. 2012.

GLAT, R.; PLETSCH; M. D. Estratégias educacionais diferenciadas para alunos com necessidades especiais. Rio de Janeiro: EdUERJ, 2013.

GLAT, R.; VIANNA, M. M.; REDIG, A. G. Plano Educacional Individualizado: uma estratégia a ser construída no processo de formação docente. Ci. Huma. e Soc. em Rev., Rio de Janeiro, v. 34, n. 12, p. 79-100, 2012.

GÓES, M. C. R.; LAPLANE, A. L. F. Políticas e práticas de educação inclusiva. Campinas, SP: Autores Associados, 2013.

KASSAR, M. C.; GÓES, M. C. R. Sobre inclusão, políticas públicas e práticas pedagógicas. In: GÓES, M. C. R.; LAPLANE, A. L. F. Políticas e práticas de educação inclusiva. 2. ed. Campinas: Autores Associados, 2007. p. 49-68. 
LANCILLOTTI, S. S. P. O trabalho didático na educação de alunos com deficiência mental: a experiência pioneira de Helena Antipoff. In: SEMINÁRIO INTERNACIONAL AMÉRICA PLATINa, 3., 2010, Campo Grande. Anais [...]. Campo Grande, MS: UFMS, 2010.

MATO GROSSO DO SUL. Lei n. 4.621, de 22 de dezembro de 2014. Plano Estadual de Educação. Campo Grande, 2014. Disponível em: http://www.sed.ms.gov.br/wpcontent/uploads/2015/05/pee-ms-2014.pdf. Acesso em: 16 out. 2017.

NERES C. C. As instituições especializadas e o movimento de inclusão: intenções e práticas. Orientadora: Maria Luisa Sprovieri Ribeiro. 2010. 158 f. Tese (Doutorado em Educação) - Universidade de São Paulo, São Paulo, 2010.

NERES, C. C.; CORRÊA, N. M. A Educação Especial na Rede Municipal de Ensino de Campo Grande - MS: um esboço de política pública em tempos de inclusão escolar. In: SEMINÁRIO NACIONAL DE ESTUDOS E PESQUISAS, 8., 2009, Campinas. Anais [...]. Campinas: UNICAMP, 2009.

\section{ORGANIZAÇÃO DAS NAÇÕES UNIDAS (ONU). Convenção sobre os direitos das} pessoas com deficiência. Aprovada pela Assembleia Geral da ONU em dezembro de 2006. 2006. Disponível em: https://www.gov.br/mdh/pt-br/navegue-por-temas/atuacaointernacional/relatorios-internacionais-1/convencao-internacional-sobre-os-direitos-daspessoas-com-deficiencia. Acesso em: 18 fev. 2019.

PACHECO, J. Caminhos para a inclusão: um guia para o aprimoramento da equipe escolar. Porto Alegre: Artmed, 2007.

PLESTCH, M. D. Repensando a inclusão escolar: diretrizes políticas e práticas curriculares e deficiência intelectual. rev. Rio de Janeiro: NAU: EDUR, 2014.

POKER, R. B. et al. Plano de desenvolvimento individual para atendimento educacional especializado. São Paulo: Cultura Acadêmica, 2013.

RODRIGUES, C. Formas criativas para estimular a mente de alunos com deficiência. Revista Nova Escola, Edição 223, jun. 2009. Disponível em:

http://revistaescola.abril.com.br/inclusao/educacao-especial/formas-criativas-estimular-mentedeficientes-intelectuais-476406.shtml?page=all. Acesso em: 10 abr. 2018.

VALADÃO, G. T. Planejamento educacional individualizado na educação especial: proposta oficial dos Estados Unidos, França, Itália e Espanha. Orientadora: Enicéia Gonçalves Mendes. 2010. 130 f. Dissertação (Mestrado em Ciências Humanas) - Universidade Federal de São Carlos, São Carlos, 2010.

VALADÃO, G. T.; MENDES, E. G. Inclusão escolar e o planejamento educacional individualizado: estudo comparativo sobre práticas de planejamento em diferentes países. Revista Brasileira de Educação, Rio de Janeiro, v. 23, 2018. 


\section{Como referenciar este artigo}

BASSI, T. M. S.; BRITO, V. M.; NERES, C. C. O plano educational individualizado e a escolarização dos alunos com deficiência intelectual: políticas e práticas. Revista on line de Política e Gestão Educacional, Araraquara, v. 24, n. esp. 2, p. 1015-1034, set. 2020. e-ISSN: 1519-9029. DOI: https://doi.org/10.22633/rpge.v24iesp2.14329

Submetido em: 30/04/2020

Revisões requeridas em: $26 / 06 / 2020$

Aprovado em: 30/07/2020

Publicado em: 30/09/2020 